\title{
Routine blood examinations combined with morphological analysis for the diagnosis of myelodysplastic/myeloproliferative neoplasms
}

\author{
HUANLING WU ${ }^{1}$, HUI SUN ${ }^{1}$, ZHIFEN ZHANG ${ }^{1}$, XIANGLI LI ${ }^{2}$, \\ YUANTANG LI ${ }^{1}$, LI LI ${ }^{1}$, RUI XU ${ }^{1}$, ZIE WANG ${ }^{1}$ and WENJUN TIAN ${ }^{1}$ \\ ${ }^{1}$ Department of Clinical Laboratory Medicine, Shandong Provincial Hospital Affiliated to Shandong University, \\ Jinan, Shandong 250021; ${ }^{2}$ Department of Clinical Laboratory, Hospital of Traditional \\ Chinese Medicine, Shouguang, Shandong 262700, P.R. China
}

Received September 22, 2015; Accepted August 5, 2016

DOI: $10.3892 / \mathrm{ol} .2016 .5165$

\begin{abstract}
In 2008, the World Health Organization (WHO) introduced a new hematological neoplasm category; myelodysplastic/myeloproliferative neoplasms (MDS/MPN), which included four main subcategories. This disease is often misdiagnosed, which delays effective therapy. The present study evaluated the role of routine blood examinations and morphological analysis of peripheral blood cells in the reliable diagnosis of MDS/MPN. In total, 236 adult MDS/MPN patients were analyzed. The analysis included 10 routine blood parameters measured using a Sysmex XE-2100 ${ }^{\mathrm{TM}}, 3$ differential percentage parameters and 7 morphological features of peripheral blood cells which were analyzed by optical microscopy, and 3 differential absolute count numbers obtained based on the corresponding differential percentages and absolute count of blood cells. The parameters were compared among the subcategories and a value of $\mathrm{P}<0.05$ was considered to indicate a statistically significant difference. The median white blood cell and hemoglobin counts of the patients were $18.0 \times 10^{9} / 1$ and $88 \mathrm{~g} / 1$, respectively. The proportion of monocytes increased to $8 \%\left(1.82 \times 10^{9} / 1\right)$, the proportion of blast cells increased to $1 \%\left(0.5 \times 10^{9} / 1\right)$ and that of neutrophil precursors increased to $10 \%\left(1.98 \times 10^{9} / 1\right)$. A total of $87 \%$ of all patients presented with hypogranulation and $71 \%$ presented with abnormal condensed nuclear chromatin in granulocytes. Atypical monocytes were observed in $73 \%$ of all patients and Pseudo-Pelger cells were observed in 60\%. Significant
\end{abstract}

Correspondence to: Dr Huanling Wu, Department of Clinical Laboratory Medicine, Shandong Provincial Hospital Affiliated to Shandong University, 324 Jingwu Weiqi Road, Jinan, Shandong 250021, P.R. China

E-mail: huanlingwudoc@163.com

Key words: myelodysplastic/myeloproliferative neoplasms, blood routine examination, morphological analysis, diagnosis differences were detected among the subcategories. The present study demonstrated that combining blood routine parameters and the morphological analysis of peripheral blood cells have an essential role in the reliable diagnosis of MDS/MPN based on WHO categories.

\section{Introduction}

In 2001, the hematopoietic and lymphoid tissue tumor classification was revised (1) to include the definition of a type of myeloid tumor known as myelodysplastic/myeloproliferative neoplasm (MDS/MPN). This type of tumor is a rare clonal myeloid neoplasm that initially presents with overlapping myelodysplastic and myeloproliferative features (1), with the incidence estimated at 0.1-3/100,000 individuals (2).

In 2008, the World Health Organization (WHO) further classified MDS/MPN into four subcategories: Juvenile myelomonocytic leukemia (JMML), atypical chronic myeloid leukemia (BCR-ABL1_negative; aCML), chronic myelomonocytic leukemia (CMML), and unclassifiable MDS/MPN (MDS/MPN-U) (3). It has been demonstrated that MDS/MPN is a heterogeneous entity at various molecular and clinical levels and has no specific molecular markers. Patients with MDS/MPN have a relatively long survival time and there is no treatment consensus except for the administration of allogenic hematopoietic stem cell transplantation (allo-HSCT, which requires a match of $\geq 3$ loci with the HLA gene) (4). The current study focused on the last three types of tumors, which include hematologic malignancies that significantly harm adult patients.

Although certain genetic mutations, including RAS, TET2, SRF2, ASXL1, SETBP1, CSF3R, SF3B1, have been detected in patients, MDS/MPN remains a challenging disease to diagnose due to its heterogeneity in clinical and laboratory features (3). Examinations of peripheral blood and bone marrow morphology are important in the diagnosis of MDS/MPN (2). The aim of the current study was to assess the importance of routine blood parameters in the reliable diagnosis of MDS/MPN, by measuring white blood cell (WBC) differential counts and the morphological features of peripheral blood cells. 
Table I. Age and male to female ratio in cases of MDS/MPN.

\begin{tabular}{|c|c|c|c|c|c|}
\hline & All patients & CMML & aCML & MDS/MPN-U & \\
\hline Parameters & $n=236$ & $\mathrm{n}=113$ & $\mathrm{n}=107$ & $\mathrm{n}=16$ & P-value \\
\hline Age, years & & & & & n.s \\
\hline Mean \pm SD & $65.2 \pm 17.5$ & $64.3 \pm 23.4$ & $67 \pm 16.3$ & $63.5 \pm 17.1$ & \\
\hline Median (range) & $70(16-87)$ & $80(18-84)$ & 70 (16-87) & $72(23-81)$ & \\
\hline Gender & & & & & $0.002^{\mathrm{a}}$ \\
\hline Male & 177 & 85 & 78 & 14 & \\
\hline Female & 59 & 28 & 29 & 2 & \\
\hline Male: female ratio & $1: 3.0$ & $1: 3.0$ & $1: 2.7$ & $1: 7.0$ & \\
\hline
\end{tabular}

${ }^{a} \mathrm{P}<0.05$, indicating a statistically significant difference; $\mathrm{n} . \mathrm{s}, \mathrm{P}>0.05$, therefore differences are not statistically significant; MDS/MPN, myelodysplastic/myeloproliferative neoplasms; CMML, chronic myelomonocytic leukemia; aCML, atypical chronic myeloid leukemia; MDS/MPN-U, unclassifiable myelodysplastic/myeloproliferative neoplasms; SD, standard deviation.

\section{Patients and methods}

Patients. Based on the 2001 and 2008 WHO hematopoietic and lymphoid tissue tumor classifications $(1,3) \mathrm{MDS} / \mathrm{MPN}$ was diagnosed in 236 patients, including 181 males and 56 females, between September 2002 and October 2013 at the Department of Clinical Laboratory Medicine, Provincial Hospital Affiliated to Shandong University (Shandong, China). There were 113 CMML, 107 aCML and 16 MDS/MPN-U cases. None of the patients were diagnosed with myelodysplastic syndrome (MDS) or myeloproliferative neoplasms (MPN), or had previously received cytokine therapy or cytotoxic drugs, which may cause the manifestation of myeloproliferative or myelodysplastic features. All patients were preliminarily diagnosed to be free of breakpoint cluster region/abelson murine leukemia viral oncogene homolog 1 (BCR/ABL), platelet derived growth factor receptors (PDGFR) $\alpha$ and $\beta$, and fibroblast growth factor receptor 1 (FGFR1) rearrangement. The present study was conducted in accordance with the declaration of Helsinki and with the approval of the Ethics Committee of the Shandong Provincial Hospital Affiliated to Shandong University. Written informed consent was obtained from all participants.

Blood routine analysis and neutrophil alkaline phosphatase (NAP). Intravenous blood was collected and mixed with $2 \mathrm{ml}$ EDTA-K2 anticoagulant. Blood was analyzed using a Sysmex XE-2100 ${ }^{\mathrm{TM}}$ Automated Hematology Analyzer (Shandong Zhixin Medical Equipment, Co., Ltd., Jinan, China). Dry blood smears were stained using the NAP method (5) and the NAP staining kit (Shenzhen Beisuo Biotechnology Company, Shenzhen, China). The percentage and score of NAP-positive cells was subsequently calculated. The 12 different parameters that were measured are presented in Table II.

Differential count and morphological analysis. Blood smears were stained using the Wright-Giemsa method. A differential white blood cell count was performed using an OLYMPUS BX51 microscope on 200 cells in the peripheral blood to determine the blast (including myeloblast, monoblasts and promonoblast), neutrophil precursor and monocyte percentages. Absolute counts were subsequently calculated. Cell morphological features were identified by staining blood films with Wright's stain. The same experts in cytomorphology centrally reviewed each blood slide at the time of diagnosis. The 13 measured parameters are presented in Tables III and IV.

Statistical analysis. All data were analyzed using the Statistical Package for the Social Sciences (SPSS) for Windows ver. 19.0 (IBM SPSS, Armonk, NY, USA). Continuous variable data are presented as mean \pm standard deviation (SD) and median and range (min-max), and count data are expressed as percentages. A one-way analysis of variance with a Bonferroni correction was used to compare continuous variables among the different groups and a $\chi^{2}$ test was applied to categorical variables. $\mathrm{P}<0.05$ was considered to indicate a statistically significant difference.

\section{Results}

Age and male to female (M:F) ratio of MDS/MPN patients. Table I presents the age and gender of the MDS/MPN patients. Median patient age was 70 years (range, 16-87) and did not differ significantly by subtype $(\mathrm{P}>0.05)$. The median $\mathrm{M}: \mathrm{F}$ ratio of MDS/MPN patients was 3.0:1 and the M:F ratio of the MDS/MPN-U group differed significantly from the other two subtypes $(\mathrm{P}=0.002$; Table I).

Routine blood parameters of the MDS/MPN patients. Table II presents the routine blood parameters of the MDS/MPN patients. The median WBC count was $18.0 \times 10^{9} / 1$ and significantly differed by subtype; the highest average blood counts were observed in the aCML group, followed by CMML, and then the MDS/MPN-U group $(\mathrm{P}=0.02)$. The median hemoglobin $(\mathrm{Hb})$ value was $88 \mathrm{~g} / \mathrm{l}$ and did not differ between different subtypes $(\mathrm{P}>0.05)$. By contrast, the median platelet (PLT) count was $116 \times 10^{9} / 1$ and differed significantly by subtype; specifically, the PLT count was significantly higher in the MDS/MPN-U group than in the other two groups $(\mathrm{P}=0.04)$. Median mean corpuscular volume (MCV) level was $88 \mathrm{fl}$, however, there were 
Table II. Routine blood parameters and the NAP scores of MDS/MPNs cases.

\begin{tabular}{|c|c|c|c|c|c|}
\hline & All patients & CMML & $\mathrm{aCML}$ & MDS/MPN-U & \\
\hline Variables & $\mathrm{N}=236(\%)$ & $\mathrm{N}=113(\%)$ & $\mathrm{N}=107(\%)$ & $\mathrm{N}=16(\%)$ & P-value \\
\hline WBC, $\times 10^{9} / 1$ & & & & & $0.02^{\mathrm{a}}$ \\
\hline Mean \pm SD & $27.8 \pm 22.1$ & $22.0 \pm 12.4$ & $36.5 \pm 24.0$ & $13.9 \pm 14.01$ & \\
\hline Median (range) & $18.0(3.4-90.5)$ & $25.7(5.0-41.2)$ & $31.4(8.4-90.5)$ & $10.2(3.4-60.2)$ & \\
\hline $\mathrm{Hb}, \mathrm{g} / \mathrm{l}$ & & & & & n.s \\
\hline Mean \pm SD & $88 \pm 25.2$ & $87 \pm 27.3$ & $92 \pm 26.2$ & $90 \pm 26.9$ & \\
\hline Median (range) & $88(43-139)$ & $89(43-137)$ & $96(51-139)$ & $92(47-158)$ & \\
\hline PLT, $\times 10^{9} / 1$ & & & & & $0.04^{\mathrm{a}}$ \\
\hline Mean \pm SD & $235 \pm 271.1$ & $143 \pm 161$ & $138 \pm 103.4$ & $396 \pm 381.6$ & \\
\hline Median (range) & $116(9-1432)$ & $88(20-382)$ & $115(9-412)$ & $249(22-1432)$ & \\
\hline $\mathrm{MCV}, \mathrm{fl}$ & & & & & 0.05 \\
\hline Mean \pm SD & $89 \pm 15.4$ & $97 \pm 11.0$ & $91 \pm 14.0$ & $82 \pm 6.72$ & \\
\hline Median (range) & $88(60.5-125)$ & $95(79-115)$ & $88(65-119)$ & $80(60.5-125)$ & \\
\hline RDW, \% & & & & & n.s \\
\hline Mean \pm SD & $18.2 \pm 4.46$ & $18.2 \pm 3.85$ & $17.5 \pm 2.28$ & $18.7 \pm 6.71$ & \\
\hline Median (range) & $17.3(12.5-34.5)$ & $18.1(11.9-25.5)$ & $17.2(12.5-22.5)$ & $16.7(12.5-34.5)$ & \\
\hline PDW, $\%$ & & & & & 0.05 \\
\hline Mean \pm SD & $13.2 \pm 3.95$ & $13.5 \pm 4.31$ & $12.7 \pm 4.29$ & $14.6 \pm 3.17$ & \\
\hline Median (range) & $12.5(6.5-21.5)$ & $11(9.6-20.9)$ & $11.5(6.5-21.5)$ & $14.5(8.5-21.5)$ & \\
\hline Eosinophil ratio, $\%$ & & & & & n.s \\
\hline Mean \pm SD & $1.1 \pm 1.30$ & $1.4 \pm 0.75$ & $0.9 \pm 1.83$ & $0.8 \pm 1.76$ & \\
\hline Median (range) & $0.4(0-8)$ & $0.5(0-6.3)$ & $0(0-8)$ & $0(0-7)$ & \\
\hline Eosinophil count, $\mathrm{x} 10^{9} / 1$ & & & & & n.s \\
\hline Mean \pm SD & $1.4 \pm 0.54$ & $2.7 \pm 0.75$ & $0.2 \pm 0.4$ & $0.1 \pm 0.13$ & \\
\hline Median (range) & $0.8(0-8.8)$ & $1.6(0-8.8)$ & $0(0-1.3)$ & $0(0-0.46)$ & \\
\hline Basophil ratio, $\%$ & & & & & n.s \\
\hline Mean \pm SD & $0.68 \pm 0.83$ & $0.49 \pm 0.20$ & $0.76 \pm 1.37$ & $1.51 \pm 1.80$ & \\
\hline Median (range) & $0.28(0-7)$ & $0.45(0-2)$ & $0(0-5)$ & $1.05(0-7)$ & \\
\hline Basophil count, $\mathrm{x} 10^{9} / 1$ & & & & & n.s \\
\hline Mean \pm SD & $0.56 \pm 0.48$ & $0.94 \pm 0.45$ & $0.26 \pm 0.60$ & $0.003 \pm 0.008$ & \\
\hline Median (range) & $0.38(0-2.6)$ & $0.80(0-1.9)$ & $0(0-2.6)$ & $0(0-0.03)$ & \\
\hline Positive rate of NAP, $\%$ & & & & & n.s \\
\hline Mean \pm SD & $43 \pm 28$ & $35 \pm 24$ & $54 \pm 27$ & $47 \pm 42$ & \\
\hline Median (range) & $40(8-96)$ & $44(8-72)$ & $57(26-80)$ & $47(10-96)$ & \\
\hline NAP score & & & & & $0.02^{\mathrm{a}}$ \\
\hline Mean \pm SD & $96 \pm 97$ & $59 \pm 51$ & $96 \pm 79$ & $143 \pm 143$ & \\
\hline Median (range) & $74(10-365)$ & $40(10-148)$ & $69(34-185)$ & $160(10-365)$ & \\
\hline
\end{tabular}

${ }^{\mathrm{a}} \mathrm{P}<0.05$, indicating a statistically significant difference; n.s, $\mathrm{P}>0.05$, therefore differences are not statistically significant. NAP, Neutrophil alkaline phosphatase; MDS/MPN, myelodysplastic/myeloproliferative neoplasms; CMML, chronic myelomonocytic leukemia; aCML, atypical chronic myeloid leukemia; MDS/MPN-U, unclassifiable myelodysplastic/myeloproliferative neoplasms; WBC, white blood cells; $\mathrm{HB}$, hemoglobin; PLT, platelet count; MCV, mean corpuscular volume; RDW, red blood cell distribution width; PDW, platelet distribution width; SD, standard deviation.

no significant differences in MCV levels among the subtypes $(\mathrm{P}>0.05)$. This was also the case with median platelet distribution width (PDW) levels. The eosinophil and basophil count and the red blood cell distribution width (RDW) were in the normal range and did not significantly differ among subtypes $(\mathrm{P}>0.05)$.
The average positive rate and NAP score of all patients were $40 \%$ and 74 points, respectively, and were within the normal range. The NAP score of the MDS/MPN-U group was 160 points, which was significantly higher than those observed in other groups $(\mathrm{P}=0.02)$. 


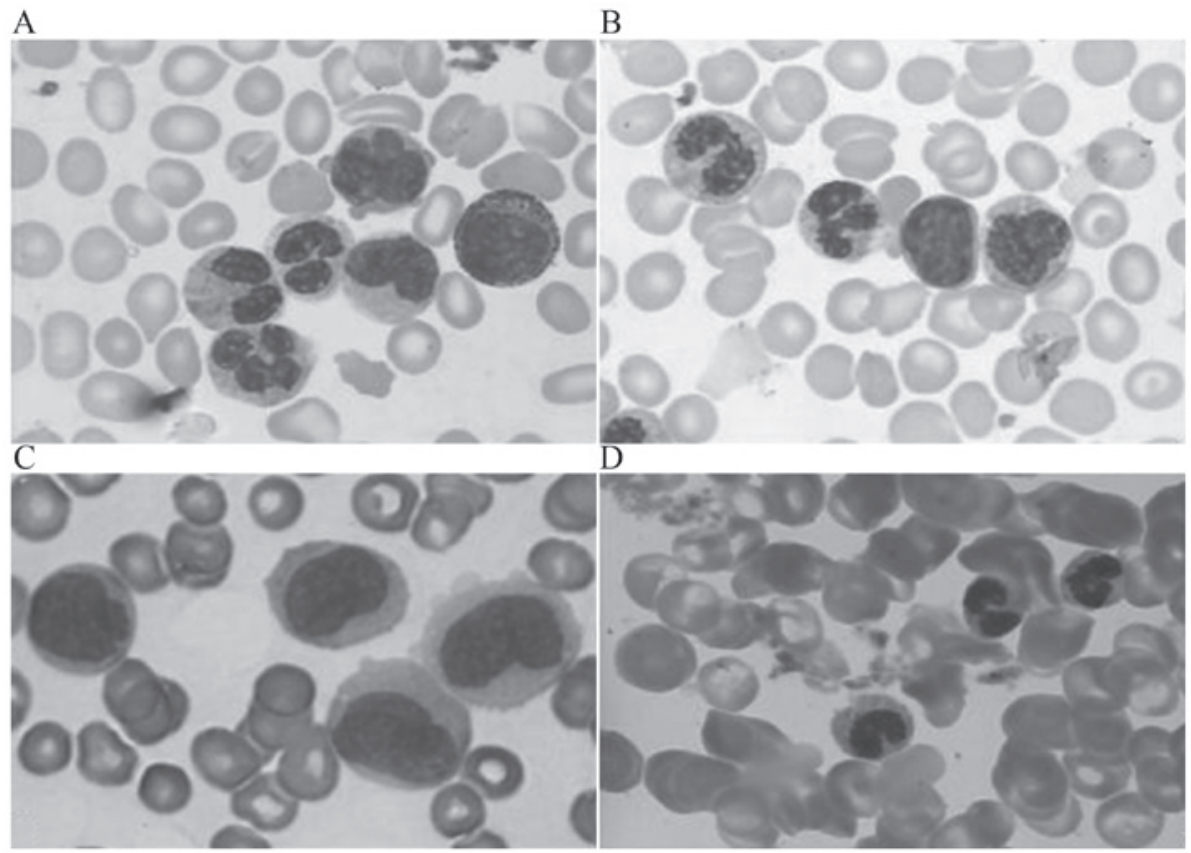

Figure 1. Morphology of peripheral blood cells from the patients. (A) Morphology of peripheral blood cells from a CMML patient. Atypical monocytes, immature granulocytes and Pseudo-Pelger-cells are presented. (B) Morphology of peripehral blood cells from an aCML patient. Blasts, Pseudo-Pelger-cells and atypical monocytes are presented. (C) Morphology of peripheral blood cells from an AML-M5 patient. Promonocytes may be observed. (D) Morphology of cells from a MDS/MPNs-U patient. Pseudo-Pelger-cells and polyplastocytosis may be observed (staining, all Wright-Giemsa; magnification, all x1250). CMML, chronic myelomonocytic leukemia; aCML, atypical chronic myeloid leukemia; AML-M5, acute monocytic leukemia; MDS/MPNs-U, unclassifiable myelodysplastic/myeloproliferative neoplasms.

Differential count of the peripheral blood cells. Table III presents the peripheral blood cell differential count. The absolute count and percentage of monocytes in the peripheral blood of MDS/MPN patients increased significantly and differed by subtype $(\mathrm{P}=0.02, \mathrm{P}=0.02$, respectively; $\mathrm{CMML}$ group $>\mathrm{aCML}$ group $>\mathrm{MDS} / \mathrm{MPN}-\mathrm{U}$ group). The percentage and absolute counts of blasts in the peripheral blood were also increased, however there were no significant differences among the subtypes. The proportion of neutrophil precursors in the peripheral blood increased to $10 \%,\left(1.98 \times 10^{9} / 1\right)$ and significantly differed by subtype (aCML group $>C M M L$ group $>M D S / M P N-U$ group; $\mathrm{P}=0.02)$.

Morphologicalfeatures of peripheral blood cells in MDS/MPN patients. Table IV presents the morphological features of MDS/MPN patients. The morphological features of peripheral blood cells were analyzed in detail and it was observed that $47 \%$ of the patients presented with blasts and $83 \%$ presented with neutrophile precursors. A total of $73 \%$ of all patients presented with atypical monocytes and these abnormal cells were most frequently observed in the CMML group $(\mathrm{P}=0.02)$. Moreover, Pseudo-Pelger cells were observed in $60 \%$ of patients, most frequently in the MDS/MPN-U group ( $\mathrm{P}=0.04)$. Furthermore, $71 \%$ of all patients presented with abnormal condensed nuclear chromatin and hypogranulation in granulocytes, and $68 \%$ presented with nucleus-cytoplasm synchrony in granulocytes, particularly in neutrophil precusors.

\section{Discussion}

MDS/MPN is a newly defined independent hematological malignancy. Currently, its diagnosis primarily depends on analyses performed in the clinic and laboratory. Certain genetic characteristics of MDS/MPN have been documented $(3,4)$, however, the diagnosis of this disease lacks specific markers. The present study demonstrated that routine blood examinations, combined with WBC differential counts and morphological analyses of peripheral blood cells, are important in the diagnosis of MDS/MPN.

An innate characteristic of MDS/MPN is that it exhibits overlapping dysplastic and proliferative features simultaneously (3). In the present study, the median age, M:F ratio, WBC count and platelet count of all patients were 70 years, $3.0: 1,19.8 \times 10^{9} / 1$ and $116 \times 10^{9} / 1$ (range, $9-1432 \times 10^{9} / 1$ ), respectively. These data differ slightly from that of a previous study, which were 58 years, $1.65: 1,18.0 \times 10^{9} / 1$ and $158 \times 10^{9} / 1$, respectively (6). This difference may be due to a larger number of patients included in the current study and the fact that patients with JMML were excluded. Within the subtypes of MDS/MPN, the WBC count of CMML group (25.7x10\%/1; range, $\left.11-23 \times 10^{9} / 1\right)$ is slightly higher than counts reported in previous studies. The median age of CMML group was 80 years (range, 18-84 years), higher than the median ages of 57-72 years reported in previous studies (6). In the present study, the platelet count was $88 \times 10^{9} / 1$, lower than in previous reports where it varied from $197-220 \times 10^{9} / 1$ (7-10). In the aCML group, the median age, $\mathrm{M}: \mathrm{F}$ ratio, $\mathrm{WBC}$ count and platelet count were 70 years, $2.7: 1,31.4 \times 10^{9} / 1$ and $115 \times 10^{9} / 1$, respectively, in the current study, whereas in previous studies, these parameters all tended to be lower; 68-72 years, $0.85: 1$ to no gender tendency, $24-40.8 \times 10^{9} / 1$ and $112 \times 10^{9} / 1$, respectively (11-16). In the MDS/MPN-U group, these parameters were 72 years, $7.0: 1,10.2 \times 10^{9} / 1$ and $249 \times 10^{9} / 1$ (ranging from $\left.22-1432 \times 10^{9} / 1\right)$ in the present study, whereas in previous 
Table III. Differential counts of peripheral blood cells in MDS/MPNs cases.

\begin{tabular}{|c|c|c|c|c|c|}
\hline & All patients & CMML & $\mathrm{aCML}$ & MDS/MPN-U & \\
\hline Variables & $\mathrm{n}=236(\%)$ & $\mathrm{n}=113(\%)$ & $\mathrm{n}=107(\%)$ & $\mathrm{n}=16(\%)$ & P-value \\
\hline Monocyte ratio, $\%$ & & & & & $0.02^{\mathrm{a}}$ \\
\hline Mean \pm SD & $11.1 \pm 8.92$ & $24.0 \pm 8.19$ & $6.4 \pm 2.61$ & $6.7 \pm 5.47$ & \\
\hline Median (range) & $8.0(1-39)$ & $24.0(15-39)$ & $6.5(1-10)$ & $5.5(0-20)$ & \\
\hline Monocyte count, $\mathrm{x} 10^{9} / 1$ & & & & & $0.02^{\mathrm{a}}$ \\
\hline Mean \pm SD & $2.5 \pm 3.02$ & $5.7 \pm 5.2$ & $3.4 \pm 5.33$ & $0.7 \pm 0.12$ & \\
\hline Median (range) & $1.82(0.1-16.1)$ & $4.2(1.2-16.1)$ & $2.0(0.2-26.0)$ & $0.8(0-1.8)$ & \\
\hline Blast ratio, $\%$ & & & & & 0.05 \\
\hline Mean \pm SD & $1.7 \pm 2.13$ & $0.6 \pm 1.13$ & $3.5 \pm 2.20$ & $0.2 \pm 0.51$ & \\
\hline Median (range) & $1(0-9)$ & $0(0-3)$ & $2(0-9)$ & $0(0-2)$ & \\
\hline Blast count, $x 10^{9} / 1$ & & & & & 0.05 \\
\hline Mean \pm SD & $0.50 \pm 0.65$ & $0.55 \pm 1.13$ & $0.87 \pm 0.68$ & $0.05 \pm 0.19$ & \\
\hline Median (range) & $0.19(0-2.72)$ & $0(0-3)$ & $0.81(0-2.72)$ & $0(0-1)$ & \\
\hline Neutrophil precusor ratio, $\%$ & & & & & $0.02^{\mathrm{a}}$ \\
\hline Mean \pm SD & $9.8 \pm 8.46$ & $9.1 \pm 13.2$ & $14.2 \pm 4.46$ & $1.9 \pm 1.89$ & \\
\hline Median (range) & $10(0-24)$ & $3(0-20)$ & $14(8-24)$ & $1(0-6)$ & \\
\hline Neutrophil precursor count, $x 10^{9} / 1$ & & & & & $0.02^{\mathrm{a}}$ \\
\hline Mean \pm SD & $3.26 \pm 3.66$ & $1.37 \pm 2.85$ & $53.7 \pm 70.54$ & $0.43 \pm 0.91$ & \\
\hline Median (range) & $1.98(0-278.7)$ & $0.28(0-8.8)$ & $9.14(0.97-278.7)$ & $0.11(1-3.6)$ & \\
\hline
\end{tabular}

${ }^{\mathrm{a}} \mathrm{P}<0.05$, indicating a statistically significant difference. MDS/MPN, myelodysplastic/myeloproliferative neoplasms; CMML, chronic myelomonocytic leukemia; aCML, atypical chronic myeloid leukemia; MDS/MPN-U, unclassifiable myelodysplastic/myeloproliferative neoplasms; $\mathrm{SD}$, standard deviation.

Table IV. Presence of morphology features of peripheral blood cells in percentages of the MDS/MPNs cases.

\begin{tabular}{|c|c|c|c|c|c|}
\hline & All patients & CMML & $\mathrm{aCML}$ & MDS/MPN-U & \\
\hline Variables & $\mathrm{n}=236(\%)$ & $\mathrm{n}=113(\%)$ & $\mathrm{n}=107(\%)$ & $\mathrm{n}=16(\%)$ & P-value \\
\hline Blasts & 47 & 10 & 91 & 11 & $0.002^{\mathrm{a}}$ \\
\hline Neutrophile precusors & 83 & 67 & 100 & 80 & n.s \\
\hline Atypical monocytes & 73 & 91 & 66 & 30 & $0.02^{\mathrm{a}}$ \\
\hline $\begin{array}{l}\text { Nucleus-cytoplasm } \\
\text { synchrony of granulocytes }\end{array}$ & 68 & 58 & 84 & 47 & $0.04^{\mathrm{a}}$ \\
\hline $\begin{array}{l}\text { Abnormal condensed nuclear } \\
\text { chromatin of granulocytes }\end{array}$ & 71 & 67 & 77 & 70 & n.s \\
\hline Hypogranulation & 87 & 87 & 88 & 87 & n.s \\
\hline Pseudo-Pelger cells & 60 & 51 & 67 & 80 & 0.05 \\
\hline
\end{tabular}

${ }^{a} \mathrm{P}<0.05$, indicating a statistically significant difference. $\mathrm{n} . \mathrm{s}, \mathrm{P}>0.05$, therefore differences are not statistically significant. MDS/MPN, myelodysplastic/myeloproliferative neoplasms; CMML, chronic myelomonocytic leukemia; aCML, atypical chronic myeloid leukemia; MDS/MPN-U, unclassifiable myelodysplastic/myeloproliferative neoplasms.

studies, they were 68-70 years, $1.0: 1-2.5: 1,7.5-17 \times 10^{9} / 1$, $100-653 \times 10^{9} / 1$, respectively $(6,15,17-19)$.

All the results suggest that MDS/MPN is a type of disease that generally occurs in the elderly, with a high male incidence rate (although the M:F ratio of aCML remains uncertain), elevated counts of WBC and varying platelet counts. The WBC count in the aCML group is higher than in the other subtypes and the platelet counts greatly vary (range from $22-1432 \times 10^{9} / 1$ ).

In the present study, the differential counts of peripheral blood cells in MDS/MPN patients obtained demonstrated that $47 \%$ of MDS/MPN patients presented with myeloblasts and $83 \%$ presented with neutrophil precursors. The median 
proportion of monocytes was elevated to $8 \%\left(1.82 \times 10^{9} / 1\right)$, the median level of blasts was $1 \%\left(0.19 \times 10^{9} / 1\right)$ and the proportion of neutrophil precursors was $10 \%\left(1.98 \times 10^{9} / 1\right)$. In the CMML group, the median proportion of monocytes was $24 \%$ $\left(4.2 \times 10^{9} / 1\right)$, which was the highest among the three subtypes and the median proportion of blasts and neutrophil precursors were $0.6 \%$ and $3 \%$, respectively. This is similar to proportions observed within this group in previous studies (7-10). Therefore, all results indicate the percentage of monocytes in CMML patients is $>10 \%$, the percentage of blasts is $<5 \%$ and neutrophil precursors make up $<10 \%$ in peripheral blood.

In the current study, the median proportion of monocytes, blasts and neutrophil precursors were 6.5\% $\left(2.0 \times 10^{9} / 1\right), 3.5 \%$ and $14 \%$ in the aCML group, compared with $2.46-10 \%, 3.3 \%$ and $6.27-10.5 \%$, respectively, in previous studies (3,11-15). The results indicate the percentage of monocytes in the peripheral blood of aCML patients is $<10 \%$ (but may exceed $1.0 \times 10^{9} / 1$ ), the percentage of blasts is $<5 \%$ and the proportion of neutrophil precursors is $5-15 \%$. In the MDS/MPN-U group, these parameters were $5.5 \%\left(0.8 \times 10^{9} / 1\right), 0.2 \%\left(0.05 \times 10^{9} / 1\right)$ and $1.9 \%$ $\left(0.43 \times 10^{\%} / 1\right)$ in the present study, and were $6 \%\left(0.45 \times 10^{9} / 1\right)$, $1 \%$ and $4.5 \%$ in previous studies, respectively (6).

The results from differential counts demonstrate that the MDS/MPN patients exhibit a high proportion of monocytes, a low percentage of blast cells and nearly $10 \%$ neutrophil precursors. The presence of blasts and neutrophil precursors are frequent features in peripheral blood smears of patients with MDS/MPN and their percentages, together with the proportion of monocytes, are important for the diagnosis of MDS/MPN subtypes.

According to the current study, not only are the number of $\mathrm{WBC}$ and proportion of monocytes and nuetrophil precursors increased in MDS/MPN patients, their morphological features are altered. Atypical monocytes were frequently observed, particularly in CMML patients.

Atypical monocytes differ from promonocytes and monoblasts. They contain no nucleolus, exhibit swelling, abnormally folded nuclei, aggregated chromatin, nucleus-cytoplasm asynchrony, variably basophilic plasma, hypo/hypergranulation and tumor-like changes $(20,21)$ (Fig. 1A and B). Promonocytes exhibit clear nucleoli, mildly folding nuclei, immature chromatin (particle mesh without obvious aggregation) and a basophilic cytoplasm (Fig. 1C). By contrast, mature monocytes exhibit an inconspicuous or absent nucleolus, obviously folding nuclei and aggregated chromatin with a grey-blue cytoplasm. When considering the morphology of nuclei on a continuum, with those of mature monocytes at one end and those of immature monocytes at the other end, the morphological features of atypical monocyte nuclei are at the midway point.

A total of $91 \%$ of CMML patients, $66 \%$ of aCML patients and $30 \%$ of MDS/MPN-U patients presented with atypical monocytes. The features of atypical monocytes are important for the characterization of MDS/MPN and its subtypes. Furthermore, accurate identification of atypical monocytes and promonocytes is very important when distinguishing cases of CMML from those of acute myeloid leukemia (AML) (22). Promonocytes are considered as 'blast equivalents', whereas atypical monocytes are considered as more mature monocytes with dysplastic features. A diagnosis of AML should be made when blasts (including myeloblasts, monoblasts and promonocytes) $\geq 20 \%$ in the peripheral blood or bone marrow, whereas blasts in MDS/MPN should be $<20 \%$.

In the present study, it was observed that $87 \%$ of the MDS/MPN patients presented with hypogranulation and $71 \%$ with abnormal condensed nuclear chromatin. The present study demonstrated that abnormally condensed chromatin is usually presented as the uniform aggregation of accumulation of the nuclear chromatin and is frequently noted as the patchwork of the deeper and lighter staining region. This phenomenon was most frequently identified in the aCML group. Hypogranulation and abnormal condensed nuclear chromatin were the top two most frequently observed morphological changes in the granulocytes of all patients with MDS/MPN. As far as neutrophil precursors were concerned, in peripheral blood, nucleus-cytoplasm asynchrony was observed in $68 \%$ of cases. This usually presents as immature tiny chromatin, sometimes with a nucleolus but more mature cytoplasm. Nucleus-cytoplasm asynchrony is generally observed in the maturation model of the nucleus and cytoplasm of the myelocytes and metamylocytes and may be presented in the band granulocytes in MDS/MPN. Pseudo-Pelger cells are also frequently observed on blood slides (Fig. 1D). The present study demonstrated that, apart from hypogranulation, nucleus-cytoplasm asynchrony is the second most frequent detection in the aCML group and Pseudo-Pelger cells are the second most frequent feature observed in the MDS/MPN-U group. These morphological changes are rarely observed in chronic infectious diseases (23).

Atypical monocytes, hypogranulation and abnormal condensed nuclear chromatin of granulocytes, nucleus-cytoplasm asynchrony of nuetrophil precursors and Pseudo-Pelger cells are important morphological features in MDS/MPN peripheral blood when diagnosing MDS/MPN and distinguishing MDS/MPN from similar diseases (including AML and various infectious diseases). These morphological features may also help practitioners classify patients into the WHO subtypes of MDS/MPN.

Although bone marrow aspirates, chromosome karyotype analyses, immunophenotype analyses and molecular biological measurements are necessary for a conclusive diagnosis and essential in prognosis assessments of MDS/MPN (6,24-26), routine examinations of whole blood, combining peripheral blood parameters, differential counts and morphological features of peripheral blood cells are the first step and pivotal in the diagnosis and differential diagnosis of MDS/MPN and its WHO subcategories. Early and reliable diagnoses of MDS/MPN and its subtypes are currently only made in this manner. Increases of WBC count, abnormalities in morphological features of white blood cells, including a low percentage of blast cells, high percentage of monocytes, presence of atypical monocytes and certain dysplastic features in neuphile cells, are critical characteristics for the early and accurate diagnosis of MDS/MPN.

\section{Acknowledgements}

The present study was partially supported by the Construction Program of Shandong Key Clinical Laboratory [Luwei medical no. (2013) 26] and Shandong Medicine Health Project (grant no. 2014WSB01013). The authors would like to thank 
Professors BC Zhang and ZM Lu for their careful review of the draft manuscript.

\section{References}

1. Vardiman JW, Harris NL and Brunning RD: The World Health Organization (WHO) classification of the myeloid neoplasms. Blood, 100: 2292-2302, 2002.

2. Geyer JT and Orazi A: Myeloproliferative neoplasms (BCR-ABL1 negative) and myelodysplastic/myeloproliferative neoplasms: Current diagnostic principles and upcoming updates. Int J Lab Hematol 38 (Suppl 1): S12-S19, 2016.

3. Orazi A and Germing U: The myelodysplastic/myeloproliferative neoplasms: Myeloproliferative diseases with dysplastic features. Leukemia 22: 1308-1319, 2008.

4. Mughal TI, Cross NC, Padron E, Tiu RV, Savona M, Malcovati L, Tibes R, Komrokji RS, Kiladjian JJ and Garcia-Manero G, et al: An International MDS/MPN Working Group's perspective and recommendations on molecular pathogenesis, diagnosis and clinical characterization of myelodysplastic/myeloproliferative neoplasms. Haematologica 100: 1117-1130, 2015.

5. Shibata A, Bennett JM, Castoldi GL, Catovsky D, Flandrin G, Jaffe ES, Katayama I, Nanba K, Schmalzl F, Yam LT, et al Recommended methods for cytological procedures in haematology. International Committee for Standardization in Haematology (ICSH). Clin Lab Haematol 7: 55-74, 1985.

6. Wu H, Bian S, Chu J, Zhong X, Sun H, Zhang B and Lu Z: Characteristics of the four subtypes of myelodysplastic/myeloproliferative neoplasms. Exp Ther Med 5: 1332-1338, 2013.

7. Beran M, Wen S, Shen Y, Onida F, Jelinek J, Cortes J, Giles F and Kantarjian H: Prognostic factors and risk assessment in chronic myelomonocytic leukemia: Validation study of the M.D Anderson Prognostic Scoring System. Leuk Lymphoma 48: $1150-1160,2007$

8. Germing U, Strupp C, Knipp S, Kuendgen A, Giagounidis A, Hildebrandt B, Aul C, Haas R, Gattermann N and Bennett JM: Chronic myelomonocytic leukemia in the light of the WHO proposals. Haematologica 92: 974-977, 2007.

9. Parikh SA and Tefferi A: Chronic myelomonocytic leukemia: 2013 update on diagnosis, risk stratification, and management. Am J Hematol 87: 610-619, 2012.

10. Benton CB, Nazha A, Pemmaraju N and Garcia-Manero G: Chronic myelomonocytic leukemia: Forefront of the field in 2015. Crit Rev Oncol Hematol 95: 222-242, 2015.

11. Koldehoff M, Steckel NK, Hegerfeldt Y, Ditschkowski M, Beelen DW and Elmaagacli AH: Clinical course and molecular features in 21 patients with atypical chronic myeloid leukemia. Int J Lab Hematol 34: e3-e5, 2012.

12. Vardiman JW, Thiele J, Arber DA, Brunning RD, Borowitz MJ, Porwit A, Harris NL, Le Beau MM, Hellstrom-Lindberg E, Tefferi A and Bloomfield CD: The 2008 revision of the World Health Organization (WHO) classification of myeloid neoplasms and acute leukemia: rationale and important changes. Blood, 114: 937-951, 2009

13. Breccia M, Biondo F, Latagliata R, Carmosino I, Mandelli F and Alimena G: Identification of risk factors in atypical chronic myeloid leukemia. Haematologica 91: 1566-1568, 2006.
14. Xubo G, Xingguo L, Xianguo W, Rongzhen X, Xibin X, Lin W, Lei Z, Xiaohong Z, Genbo X and Xiaoying Z: The role of peripheral blood, bone marrow aspirate and especially bone marrow trephine biopsy in distinguishing atypical chronic myeloid leukemia from chronic granulocytic leukemia and chronic myelomonocytic leukemia. Eur J Haematol 83: 292-301, 2009.

15. Wang SA, Hasserjian RP, Fox PS, Rogers HJ, Geyer JT, Chabot-Richards D, Weinzierl E, Hatem J, Jaso J, Kanagal-Shamanna R, et al: Atypical chronic myeloid leukemia is clinically distinct from unclassifiable myelodysplastic/myeloproliferative neoplasms. Blood 123: 2645-2651, 2014.

16. Onida F, Ball G, Kantarjian HM, Smith TL, Glassman A, Albitar M, Scappini B, Rios MB, Keating MJ and Beran M: Characteristics and outcome of patients with Philadelphia chromosome negative, bcr/abl negative chronic myelogenous leukemia. Cancer 95: 1673-1684, 2002.

17. Triantafyllidis I, Ciobanu A, Stanca O, Draghici C, Angelescu S and Tapelea E: Peculiarities in the Diagnosis Approach of MDS/MPN-U Patients. Maedica (Buchar) 7: 173-176, 2012.

18. Seo JY, Lee KO, Kim SH, Kim K, Jung CW, Jang JH and Kim HJ: Clinical significance of SF3B1 mutations in Korean patients with myelodysplastic syndromes and myelodysplasia/myeloproliferative neoplasms with ring sideroblasts. Ann Hematol 93: 603-608, 2014

19. DiNardo CD, Daver N, Jain N, Pemmaraju N, Bueso-Ramos C, Yin CC, Pierce S, Jabbour E, Cortes JE, Kantarjian HM, et al: Myelodysplastic/myeloproliferative neoplasms, unclassifiable (MDS/MPN, U): Natural history and clinical outcome by treatment strategy. Leukemia 28: 958-961, 2014.

20. Hyjek E and Vardiman JW: Myelodysplastic/myeloproliferative neoplasms. Semin Diagn Pathol 28: 283-297, 2011.

21. Goasguen JE, Bennett JM, Bain BJ, Vallespi T, Brunning R and Mufti GJ; International Working Group on Morphology of Myelodysplastic Syndrome: Morphological evaluation of monocytes and their precursors. Haematologica 94: 994-997, 2009.

22. Hall J and Foucar K: Diagnosing myelodysplastic/myeloproliferative neoplasms: Laboratory testing strategies to exclude other disorders. Int J Lab Hematol 32: 559-571, 2010.

23. Vermi W, Facchetti F, Rosati S, Vergoni F, Rossi E, Festa S, Remotti D, Grigolato P, Massarelli G and Frizzera G: Nodal and extranodal tumor-forming accumulation of plasmacytoid monocytes/interferon-producing cells associated with myeloid disorders. Am J Surg Pathol 28: 585-595, 2004

24. Tiu RV and Sekeres MA: Making sense of the myelodysplastic/myeloproliferative neoplasms overlap syndromes. Curr Opin Hematol 21: 131-140, 2014.

25. Cazzola M,Malcovati L and Invernizzi R: Myelodysplastic/myeloproliferative neoplasms. Hematology Am Soc Hematol Educ Program 2011: 264-272, 2011.

26. Kern W, Bacher U, Schnittger S, Alpermann T, Haferlach C and Haferlach T: Multiparameter flow cytometry reveals myelodysplasia-related aberrant antigen expression in myelodysplastic/myeloproliferative neoplasms. Cytometry B Clin Cytom 84: 194-197, 2013. 